\title{
Novaferon, a novel recombinant protein produced by DNA-shuffling of IFN-a, shows antitumor effect in vitro and in vivo
}

Meng $\mathrm{Li}^{1 \dagger}$, Chunming Rao ${ }^{1 \dagger}$, Dening Pei ${ }^{1}$, Lan Wang ${ }^{1}$, Yonghong $\mathrm{Li}^{1}$, Kai Gao ${ }^{1}$, Minrong Wang ${ }^{2}$ and Junzhi Wang ${ }^{1 *}$

\begin{abstract}
Objective: A recombinant antitumor/antiviral protein (Novaferon, Nova) is a new type of interferon, which is produced by artificial design technology combining DNA-shuffling and High Throughput Screening (HTS).

Methods: The in vitro biological activities, such as anti-tumor activity and antiviral activity of Nova and recombinant human interferon alpha-2b (rhIFN-a2b) was performed; in vivo anti-tumor activity in nude mice was also tested. Flow cytometry, histo-pathological analysis including HE staining and immunohistochemistry, and surface plasmon resonance assay were performed to investigate the underlying mechanisms analysis.
\end{abstract}

Results: Nova exhibited stronger anti-cancer effects compared to rhIFN-a2b in vitro and in vivo. The antitumor mechanisms of Nova may be related to S phase arrest, pro-apoptosis, and inhibition of tumor angiogenesis. Moreover, Nova exhibited a higher binding affinity for IFN receptor 2 (IFNR2) than rhIFN-a2b, which is one of the possible reasons accounting for its stronger actions against tumor cells compared with rhlFN-a2b.

Conclusion: Nova has strong antitumor activity and could be a potentially effective therapeutic drug for cancer.

Keywords: Novaferon, Recombinant interferon-a protein, Anti-cancer, in vivo, IFN receptor 2

\section{Introduction}

Cancers are becoming a leading cause of morbidity and mortality worldwide in the coming decades. At present, the treatment of cancer is the major challenge for the global medical community [1]. With the advance of molecular biology and genetic engineering, the development of anticancer drugs has entered a new stage. Considerable progress has been made in harnessing biotechnology for the development of anticancer drugs, such as monoclonal antibodies, cytokines and interferons.

Interferon (IFN) is one of the most common biotechnology drugs which has been widely used in the adjuvant therapy of tumors [2,3]. Clinical benefits of IFN- $\alpha$ therapy includes increase in the disease-free survival by $\sim 9$ months and the 5 -year survival by $8-9 \%[4,5]$. Interferon possesses both direct tumor-killing and immunomodulatory effect [6], IFN- $\alpha$ exerts its effects mainly through the Tyk2/Jak1-
STAT1/STAT2 pathway to activate transcription from the IFN-stimulated response element (ISRE) [5]. IFN- $\alpha$ is currently the most used cytokine in the treatment of cancer. However, the potential anti-tumour activity of IFN- $\alpha$ is limited by the activation of tumour resistance mechanisms [7].

Novaferon (Nova) is a new recombinant IFNa like anti-tumor/viral protein with significantly higher activities than IFN- $\alpha$ [8]. Screened from over 10 million artificial clones of recombinant interferons. Preliminary analysis suggest it may have more strong bioactivity than normal IFN $\alpha$ and share the same mechanism on cancer treatment with interferon in cell cycle arrest, promotion of apoptosis and inhibition of oncogene expression.

In the current study, we tested Nova's bioactivities on tumor cells and virus; secondly, we also probed the mechanisms of Nova in cancer treatment.

\footnotetext{
*Correspondence: wangjz@nifdc.org.cn

'Equal contributors

${ }^{1}$ National Institutes for Food and Drug Control of China, No. 2 Tiantan Xili,

Beijing 100050, China

Full list of author information is available at the end of the article
} 


\section{Materials and methods}

Animals and cell lines

Male BALB/c nude mice, 6 weeks old, were purchased from the National Institutes for Food and Drug Control. The mice were fed under pathogen-free and humane conditions. All experiments involving the use of mice were carried out according to the protocols approved by the Animal Care and Use Committee of Academy of Military medical Sciences (Beijing, China). WISH cells (CCL-25), HepG2 (HB-8065) and Daudi cells (CCL-213) were purchased from ATCC (Manassas, VA, USA). HepG2 cells were cultured in Eagle's Minimum Essential (EME) medium (Gibco, NY, USA) supplemented with $10 \%(\mathrm{v} / \mathrm{V})$ FBS (Invitrogen, CA, USA) in a humidified atmosphere containing $5 \% \mathrm{CO} 2$ at $37^{\circ} \mathrm{C}$. WISH cells were cultured in Minimal Essential Medium (MEM) supplemented with non-essential amino acids and $10 \%(\mathrm{v} / \mathrm{v})$ FBS. Daudi cells were cultured in RPMI-1640 medium (Gibco, NY,
USA) supplemented with $10 \%(\mathrm{v} / \mathrm{v})$ FBS (Invitrogen) in a humidified atmosphere containing $5 \% \mathrm{CO} 2$ at $37^{\circ} \mathrm{C}$.

\section{Reagents}

Nova was prepared according to method described previously [9], in brief, a shuffling library with 12 subtypes of IFNos was constructed from human leukocyte cDNAs. Followed by PCR amplification, DNase I digestion and anti-tumor/virus activity screening, Novaferon, a human interferon-like protein was screened. The purity of Nova was determined by Size Exclusion Chromatography-HighPerformance Liquid Chromatography (SEC-HPLC) assay. Nova was separated by Shodex Protein KW-803 column (Showa Denko America, Inc., NY, USA) in PB buffer (20 mM Na3PO4, 0.5 mM NaCl, 0.02\% Tween80, pH7.0). The purity was calculated by division of the target peak area and the total peak area.
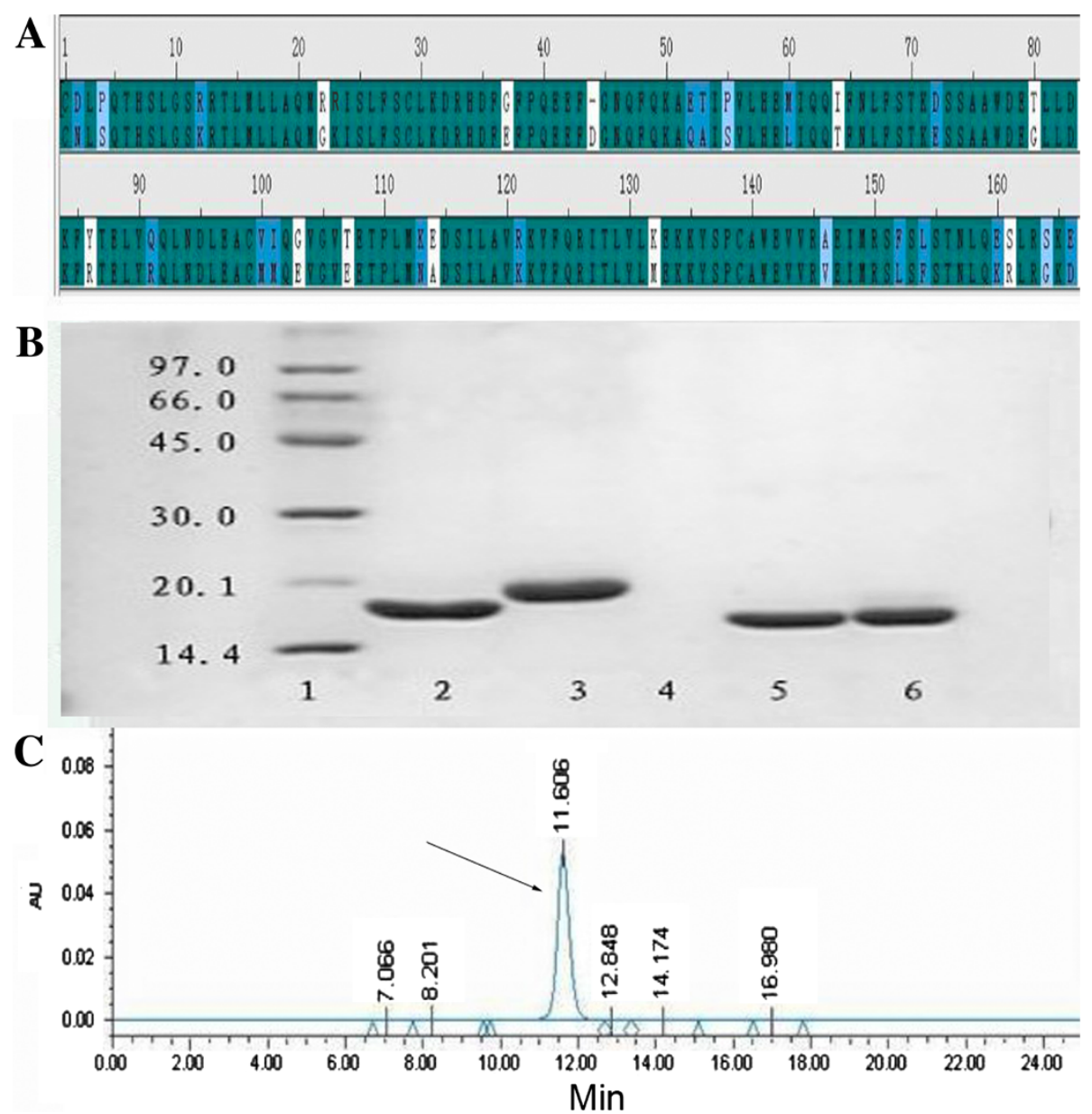

Figure 1 Sequence, molecular weight and purity of Nova. (A) Sequence alignment between IFN- $\mathrm{a} 2 \mathrm{~b}$ (upper line) and Nova (lower line); (B) SDS-PAGE separation result (stained with Commassie Brilliant Blue R-250): Lane 1, marker; Lane 2, rhIFN-a2b (Reduction), 17.51 KD; Lane 3, Nova (reduction), 19.06 KD; Lane 4, Blank; Lane 5: rhIFN-a2b (Non-reducing, 100\%); Lane 6, Nova (Non-reducing, 100\%); (C) Size-exclusion high performance liquid chromatography analysis result, arrow indicated the Nova. 
Antibody against caspase-3 cleaved fragment was purchased from Upstate Biotechnology (Temecula, CA, USA). Antibodies against Bax and Bcl-2 were purchased from Santa Cruz Biotechnology (Santa Cruz, CA, USA). Antibody against Ki-67 was purchased from Thermo Fisher Scientific (Melbourne, VIC, Australia). Antibody against $\alpha$-SMA was purchased from Abcam (Cambridge, MA, USA). Recombinant human IFN- $\alpha / \beta$ R2-Fc chimera, recombinant human IgG1 Fc and goat anti-human IgG Fc was purchased from R\&D Systems (Minneapolis, MN, USA). FITC Annexin V/ PI apoptosis kit was from BD Biosciences (Burlington, MA, USA).

\section{Antiproliferative test in Daudi cells}

For the MTT [3-(4,5-dimethylthiazol-2-yl)-2,5-diphenyltetrazolium bromide; Sigma-Aldrich, Inc., St. Louis, MO] anti-proliferative assay, Daudi cells $\left(3 \times 10^{4}\right.$ cells/ well) were treated with Nova, rhIFN- $\alpha 2 b$ and IFN- $\alpha$ international standard control at an initial concentration with 4-fold serial dilutions $(0 \sim 250 \mathrm{IU} / \mathrm{ml})$ in $10 \% \mathrm{FBS}$ RPMI as previously described [10]. Concentrations of IFNs that inhibit cell growth by $50 \%\left(\mathrm{IC}_{50}\right)$ were calculated at $48 \mathrm{~h}$ after treatment.

\section{Anti-viral activity testing by WISH/VSV assay}

Vesicular stomatitis virus (VSV) has been reported to induce apoptosis and the onset of apoptosis may play an important role in virus-associated diseases $[11,12]$. We compared anti- viral activity of Nova and rhIFN- $\alpha 2 b$ by virtue of cytopathic effect reduction assay (CPE) that employed a human amnion cell line(WISH) challenged with vesicular stomatitis virus (VSV) as described in detail elsewhere [13], inoculated WISH cells were added in a 96well plate at a density of $3 \times 10^{5}$ cells $/ \mathrm{ml}$, subsequently treated with 4 -fold serial dilutions $(0 \sim 250 \mathrm{IU} / \mathrm{ml})$ of Nova, rhIFN- $\alpha 2 b$ and IFN- $\alpha$ international standard control for $24 \mathrm{~h}$. A total of $1000 \mathrm{pfu}$ VSV was added to infect cells for $12 \mathrm{~h}$. The staining and dissolve procedures of WISH cell/VSV system were described previously [14]. Anti-tumor/viral activity of Nova and rhIFN- $\alpha 2 b$ was demonstrated as absorption value data of $550 \mathrm{~nm}$ after analyzed by Soft max program.

\section{Anti-tumor activity tested by flow cytometry}

A total of $1 \mathrm{ml} \mathrm{HepG} 2$ cells $\left(10^{5} / \mathrm{ml}\right)$ were added into a 12 -well plate, cells were treated with Nova and rhIFN- $\alpha 2 b$, untreated cells served as blank control. Twenty four hours later, the cells were stained by Propidium Iodide (PI) [15]

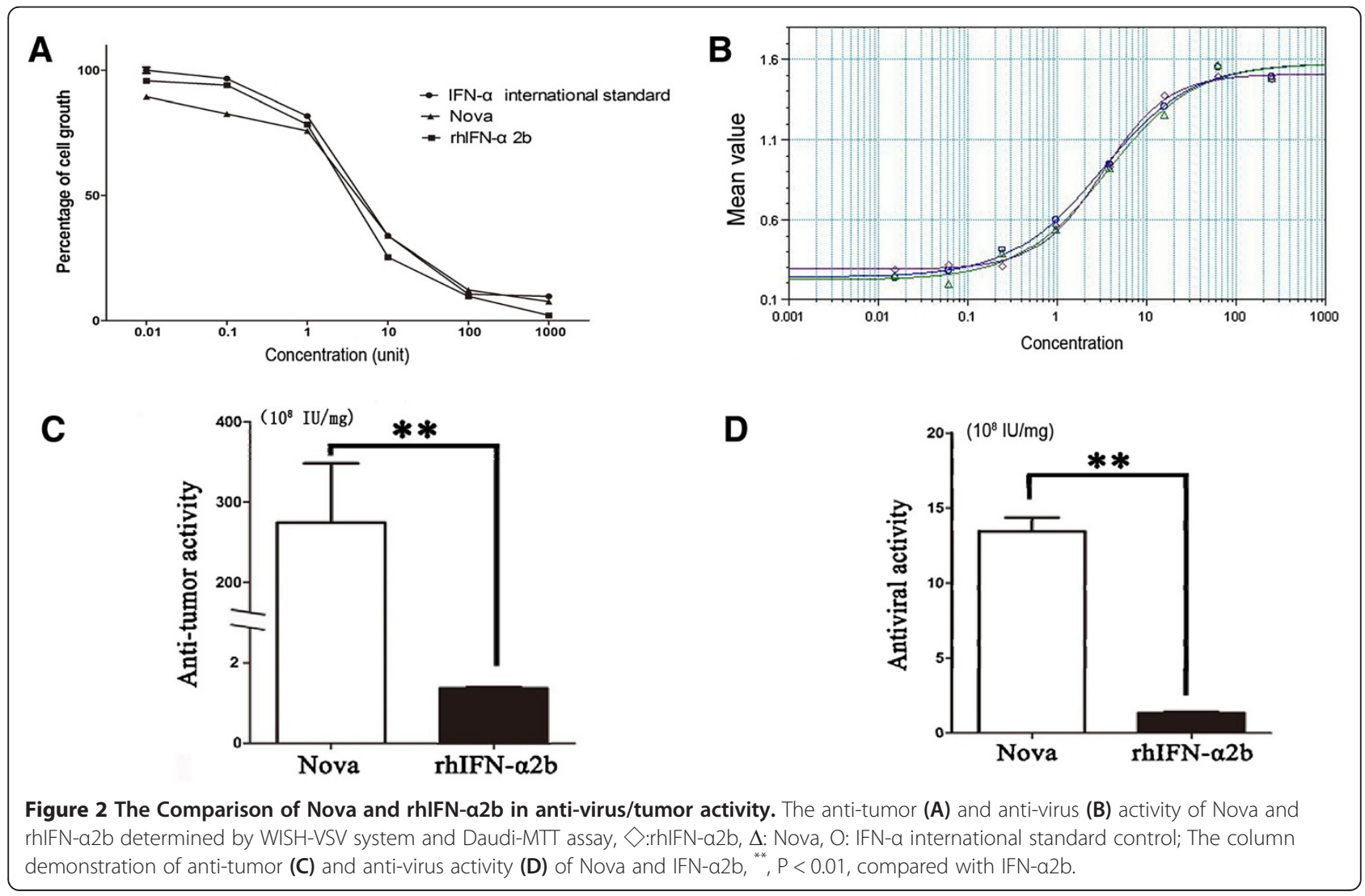




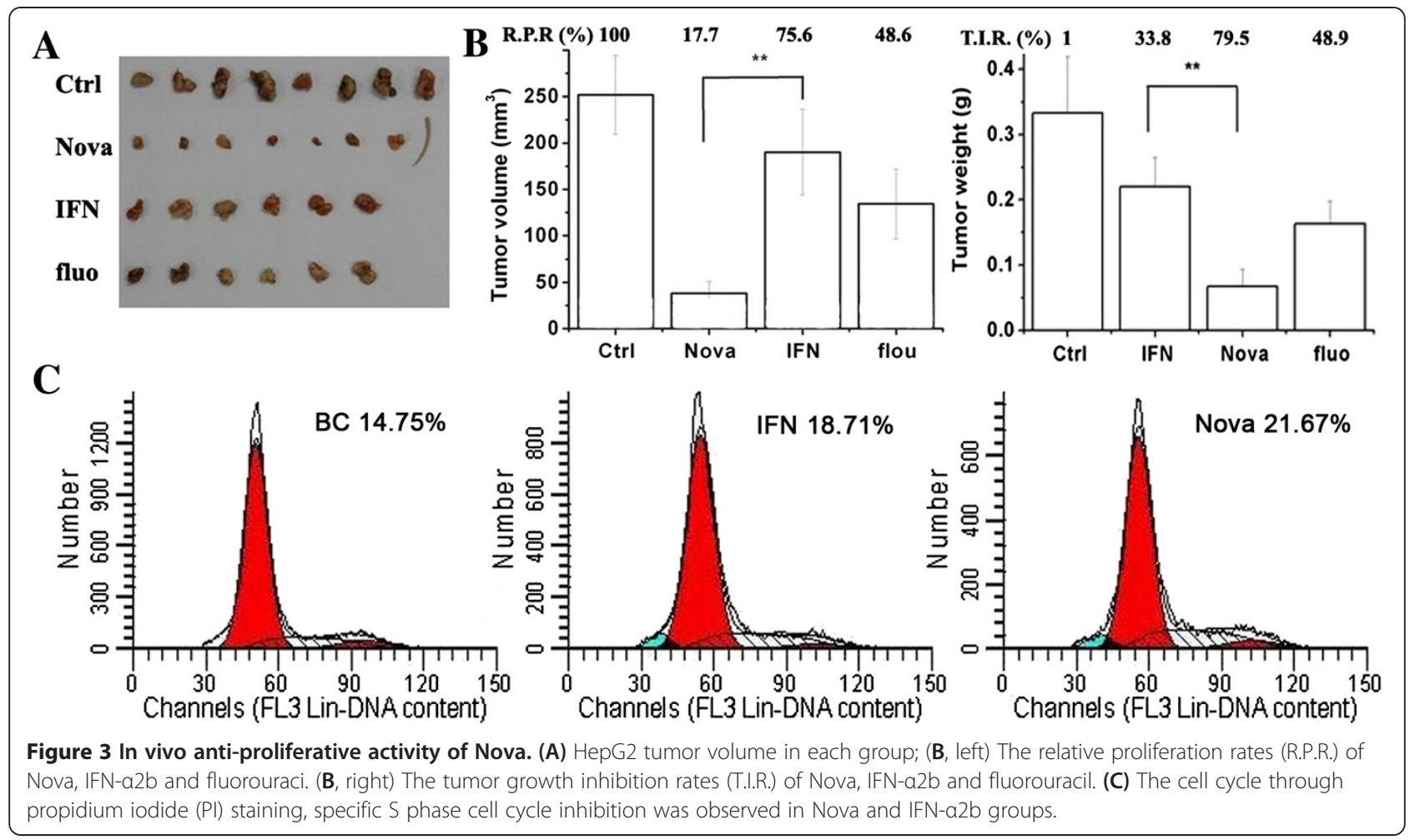

and harvested. Stained nuclei were analyzed using BD FACScan flow cytometer (Becton Dickinson, NY, USA). DNA distributions were analyzed by BD FACSDiva software (BD Biosciences, NJ, USA) for the proportions of cells in $\mathrm{S}$ phase of the cell cycle.

\section{In vivo anti-tumor activity in nude mice}

Tumors were implanted in BALB/c-nude mice (20-25 g; $\mathrm{n}=32$ ) as previously described [6]. Briefly, $100 \mu \mathrm{l}$ of HepG2 cells $\left(1 \times 10^{6}\right.$, viability of $\left.95-97 \%\right)$ were inoculated into the shoulder of right forelimb. The mice were housed one per cage with free access to sterile water and standard laboratory chow diet. When the diameter of the tumors reached to 4-5 $\mathrm{mm}$, the mice were randomly divided into four groups $(\mathrm{N}=6)$ : Nova group, rhIFN- $\alpha 2 \mathrm{~b}$ group, positive control group (fluorouracil) and negative control group (PBS). Subcutaneous injection was carried out with varied doses in different groups: Nova $250 \mu \mathrm{g} / \mathrm{kg}$, rhIFN- a2b $250 \mu \mathrm{g} / \mathrm{kg}$, fluorouracil $30 \mathrm{mg} / \mathrm{kg}$, PBS $0.1 \mathrm{ml}$. Nova, rhIFN- $\alpha 2 b$ and PBS were administrated once daily for 21 days. Fluorouracil was administrated every other day. Twenty one days later, anesthetization of sodium pentobarbital was applied to the mice and then the mice were sacrificed; RPR (relative proliferation rates) with the tumor volumes and the TIR (tumor growth inhibition rates) with the tumor weights were calculated respectively based on previously similar study [16].

\section{HE and Immunohistochemistry analysis}

Excised tumor specimens were fixed in 10\% neutralbuffered formalin. After embeded in paraffin, a series of 5 - $\mu \mathrm{m}$ sections were sliced. Sections were de-paraffinized, and rehydrated. After the sections were de-waxed by xylene and processed by graded ethanol debenzolization. They were then washed with tap water, differentiated with hydrochloric acid and ethanol before staining with
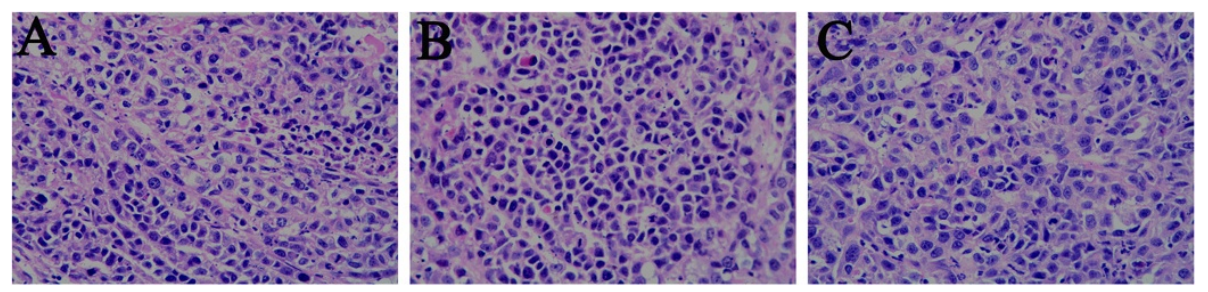

Figure $4 \mathrm{HE}$ staining was observed under the microscope (200x), compared with negative control (A) we observed karyopyknosis and shape changed in the rhIFN- a $2 B(B)$ and nova group (C). 


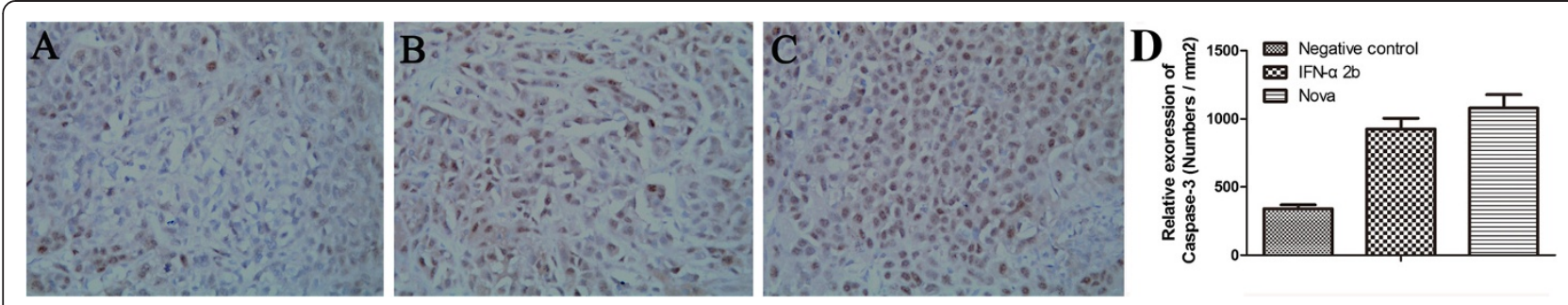

Figure $\mathbf{5}$ The immuno histochemical analysis result of caspase $\mathbf{3}$ in each group. Caspase-3 protein increased in dissected tumor tissues after mice was treated by IFN-a2b (B) and Nova (C) compared with the negative control (A). $\mathbf{D}$ is quantization of the expression of the proteins evaluated in the different samples with immunohistochemistry.

eosin for $2 \mathrm{~min}$. For Immunohistochemistry analysis, after quenching endogenous peroxidase activity and blocking nonspecific binding sites, slides were incubated at $4^{\circ} \mathrm{C}$ overnight with 1:100 dilutions of primary antibodies against $\mathrm{Bax}, \mathrm{Bcl}-2$, caspase $3, \mathrm{Ki}-67$ and $\alpha$-SMA respectively, followed by 30 -min incubation with secondary antibodies. Slides were then visualized using the DAB chromogen (Lab Vision Corp., Fremont, CA).

\section{Surface Plasmon Resonance (SPR) assay}

SPR method is one of effective methods to study direct macromolecular interactions, compared with indirect methods, such as ELISA; SPR has the real-time, rapid, and label-free characteristics. For analysis of Nova and IFN-a2b affinity for IgG, SPR studies were performed using a BIAcore T-100 (BIAcore AB, Uppsala, Sweden). Human IFNR2-Fc was captured on the CM5 chip by an immobilized anti-human IgG Fc antibody. Nova or IFN$\alpha 2 b$ was added in the solution phase, the binding was measured under equilibrium conditions. The data were analyzed by BiacoreT-100 evaluation.

\section{Results}

\section{Sequence alignment and purity of nova}

Nova shares approximately $82 \%$ sequence identity to human IFN- $\alpha 2 b$ (Figure 1A). The molecular weight of Nova was about $19 \mathrm{kDa}$ estimated by SDS-PAGE (Figure 1B). The purity of Nova was at least $99 \%$ tested by SEC-HPLC (Figure 1C).

\section{Anti-tumor/virus activity of nova}

The anti-tumor activity of Nova and IFN- $\alpha 2 b$ against Daudi cell lines was $2.74 \times 10^{10} \mathrm{U} / \mathrm{mg} \pm 8.71 \times 10^{9} \mathrm{U} / \mathrm{mg}$ $(\mathrm{n}=3)$ and $1.57 \times 10^{8} \mathrm{U} / \mathrm{mg} \pm 6.91 \times 10^{7} \mathrm{U} / \mathrm{mg}(\mathrm{n}=3)$ respectively (Figure 2A). The anti-virus activity of Nova and IFN- $\alpha 2 \mathrm{~b}$, which was verified by WISH/VSV system, was $1.34 \times 10^{9} \pm 1.57 \times 10^{8}(\mathrm{n}=3)$ and $1.34 \times 10^{8} \pm 1.48 \times 107$ $(\mathrm{n}=3)$ respectively (Figure $2 \mathrm{~B})$. Nova shared a high homology with IFN- $\alpha 2 \mathrm{~b}$, but the anti-tumor and anti-virus activity of Nova was 174-fold (Figure 2C) and 10-fold (Figure 2D) greater than IFN- $\alpha 2 b$.

\section{Enhanced inhibition of nova to Hep-G2 cell proliferation in nude mice}

To explore the anti-proliferative activity of Nova in vivo, effect of Nova on Hep-G2 cell proliferation in nude mice was tested. Result showed IFN- $\alpha 2 b$ and fluorouracil reduced the HepG2 tumor volume (Figure 3A), and was consistent with previous reports $[17,18]$. The relative proliferation rates (R.P.R.) of Nova, IFN- $\alpha 2 b$ and fluorouracil were $17.7 \%, 75.6 \%$ and $48.6 \%$, respectively (Figure 3B, left). The tumor growth inhibition rates (T.I.R.) of Nova, IFN- $\alpha 2 \mathrm{~b}$ and fluorouracil were $79.5 \%, 33.8 \%$ and $48.9 \%$, respectively (Figure 3B, right). We also analyzed the cell cycle through propidium iodide (PI) staining. Specific $\mathrm{S}$ phase cell cycle inhibition was observed in Nova (23\%) and IFN- $\alpha 2 b$ (18\%) treatment groups (Figure $3 \mathrm{C}$ ). The results showed that the anti-tumor activity of Nova, a protein originated from IFN- $\alpha$, has been enhanced.
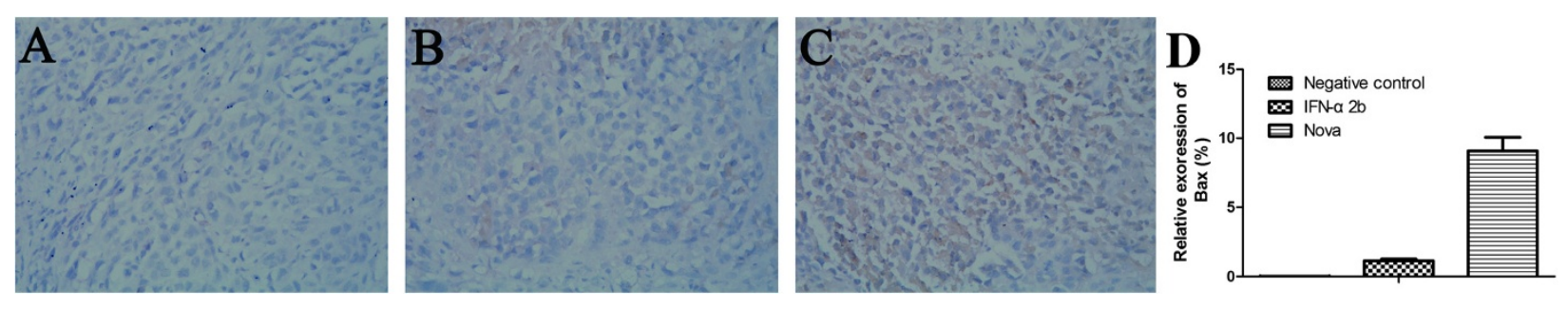

Figure 6 The immuno histochemical analysis result of Bax in each group. Bax protein increased in tumor tissues after mice was treated by IFN-a2b (B) and Nova (C) compared with the negative control (A). D is quantization of the expression of the proteins evaluated in the different samples with immunohistochemistry. 


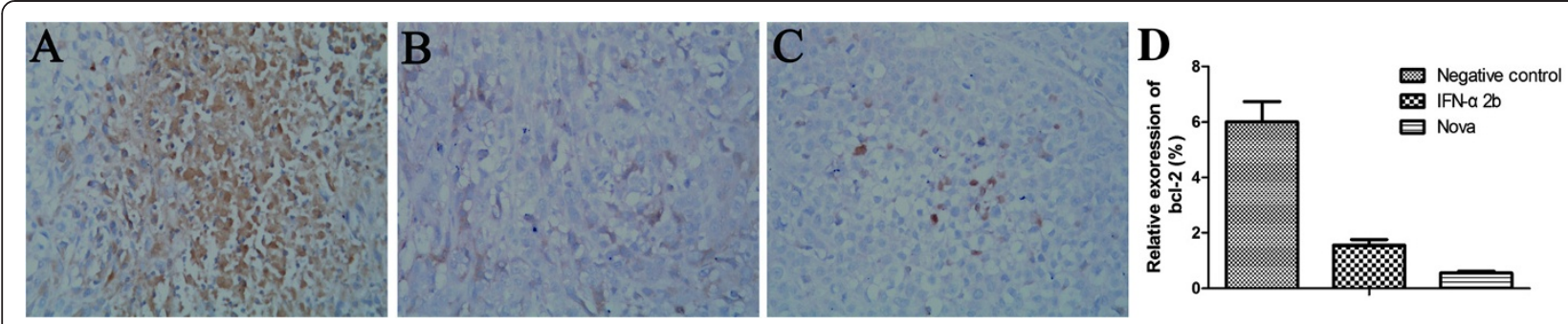

Figure 7 The immuno histochemical analysis result of $\mathbf{B c l}-2$ in each group. $\mathrm{BCl}-2$ protein decreased in tumor tissues after mice was treated by IFN-a2b (B) and Nova (C) compared with the negative control (A). D is quantization of the expression of the proteins evaluated in the different samples with immunohistochemistry.

As shown in Figure 3C, besides the cell cycle change, our study demonstrates that the apoptosis rate of the Nova was $13.07 \%$, while in rhIFN- $22 \mathrm{~b}$ group, the apoptosis rate is $9.67 \%$.

\section{Novaferon changes the expression of several apoptosis -related genes}

HE staining was observed under the microscope, compared with negative control, we found that karyopyknosis and shape change of cells existed in the tumor sample treated with rhIFN- $\alpha 2 \mathrm{~B}$ and nova (Figure 4).

Caspases, Bax and Bcl-2 proteins were extensively studied for induction of apoptosis regulation. To explore the related apoptotic mechanism of Nova, we examined the protein levels of caspase- 3 , and Bcl-2 by immunohistochemistry analysis. Result showed caspase- 3 protein increased in dissected tumor tissues after mice was treated by IFN- $\alpha 2 b$ and Nova compared with the negative control (Figure 5), the levels of caspase-3 was higher in Nova group than IFN- $\alpha 2 b$ group. The expression of Bax proteins (Figure 6) was consistent with caspase-3. On the other hand, Bcl-2 expression was down-regulated in IFN- $\alpha 2 b$ and Nova groups when compared with the control; the expression of Bcl-2 in Nova groups was less than IFN- $\alpha 2 b$ group (Figure 7). Moreover, expression of proliferation marker Ki-67 (Figure 8) and $\alpha$-smooth muscle actin ( $\alpha$-SMA, Figure 9$)$ were down-regulated in IFN- $\alpha 2 \mathrm{~b}$ and Nova groups.

\section{Binding of nova and IFN- $a 2 b$ fused to IFN receptor 2}

SPR analysis showed Nova could interact with IFN receptor 2 (IFNR2) by Biacore T-100 instrument. Binding curve showed that Nova bind to IFNR2 with higher affinity $\left(\mathrm{KD}=1.23 \times 10^{-11} \mathrm{M}\right.$ than that of rhIFN- $\alpha 2 \mathrm{~b}$ $\left(\mathrm{Kd}, 1.59 \times 10^{-9} \mathrm{M}\right)$ (Figure 10). This data demonstrates that IFNR2 is a probable receptor of Nova.

\section{Discussion}

IFNs were the first cytokines used in treating malignant tumor, with the approval of recombinant human IFNs, IFN- $\alpha 2 a$ and IFN- $\alpha 2 b$ for the treatment of Hairy Cell Leukemia and Kaposi's sarcoma [19], IFNs provide fundamental defense strategies against viral infections, tumor growth and immune disorders. We used rhIFN- $\alpha 2 b$ as a positive control to evaluate the therapeutic effect of Nova, results showed that Nova inhibited proliferation rate of the HepG2 cell in vitro and in vivo significantly. In our study, in vivo anti-cancer effect may include many mechanisms, such as immune regulation and cytokine regulation. During their cytotoxic effecting on tumor cells, IFN could activate monocytes and macrophages, thus produce free radicals (ROS) and reactive nitrogen intermediates (RNI) to exert their effect [20]. IFN can also cause decreased production of fibroblast growth factor (bFGF), and reduced transcription of vascular endothelial growth factor (VEGF) [6,21]. Therefore, in vivo tumor inhibition experiments exerted stronger inhibitory effects than in vitro tumor cell killing experiments. Moreover,
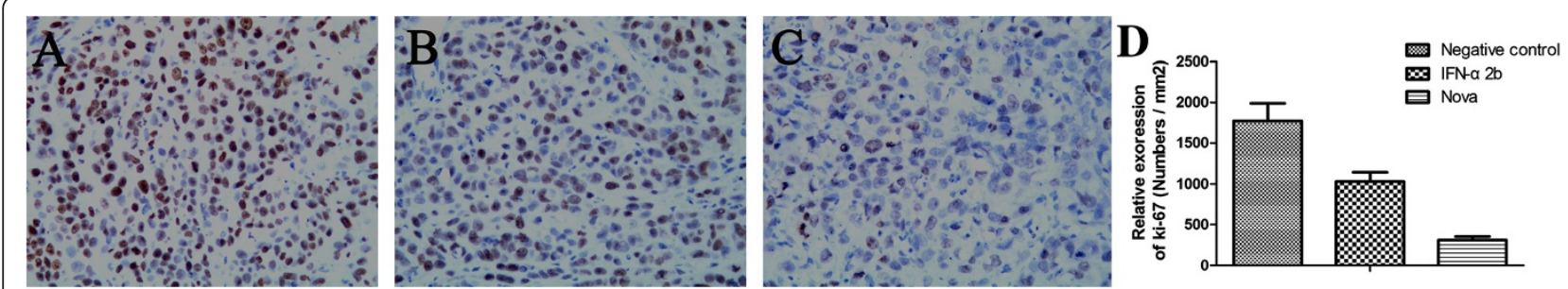

Figure 8 Ki-67protein levels ingroup of IFN-a2b (B) and Nova (C) compared with the negative control (A) by immuno histochemical analysis. $\mathbf{D}$ is quantization of the expression of the proteins evaluated in the different samples with immunohistochemistry. 


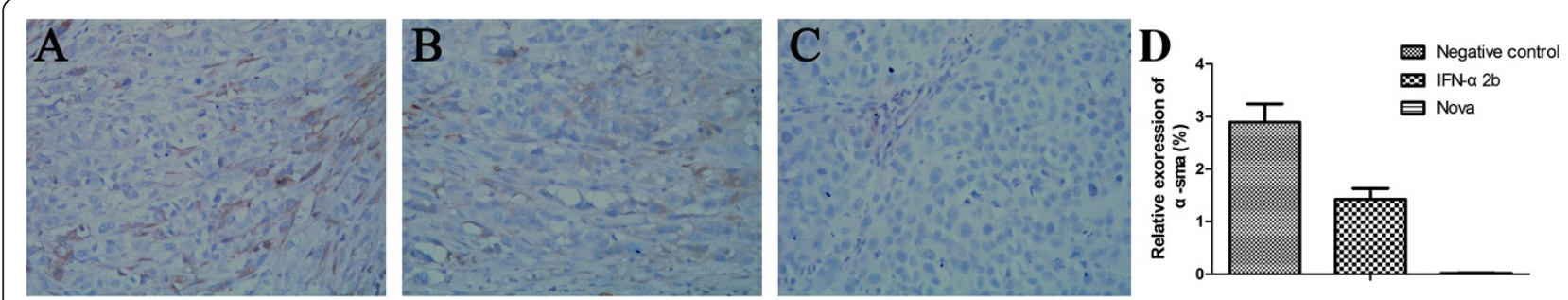

Figure 9 a-SMA protein levels in groups of IFN- $a 2 b$ (B) and Nova (C) compared with the negative control (A) by immuno histochemical analysis. $\mathbf{D}$ is quantization of the expression of the proteins evaluated in the different samples with immunohistochemistry.

Nova can interact with IFNR2 with a lower dissociation in vitro; therefore Nova could demonstrate higher biological activity than rhIFN- $\alpha 2 b$.

Interferon is known to be involved in different phases of the mitotic cycle, the most common exerted effect is on the transition from G1 to S phase [22]. Type I and type II IFNs are capable of inhibiting the expression transcription factor c-myc, which is essential for activating cyclin-dependent kinase (CDK), subsequently regulate the transition from $\mathrm{G} 1$ to $\mathrm{S}$ phase and induce transcription of a large genes necessary for $S$ phase [23]. The cell cycle analysis showed the percentage of $\mathrm{S}$ phase treated with Nova and rhIFN- $\alpha 2 \mathrm{~b}$ was $21.67 \%$ and $18.71 \%$ respectively, and the percentage of $\mathrm{S}$ phase of the blank control group was $14.75 \%$. Compared with blank control group, Nova and IFN-a2b inhibit cell cycle progression by arresting them in $\mathrm{S}$ phase, so that the percentage of cells in $\mathrm{S}$ phase is increased.

Inhibition of DNA synthesis of S phase prevents mitotic entry through the action of the S-phase key point in tumor cells. Thus we speculate that one effect of Nova on these starved cells was to slow progression

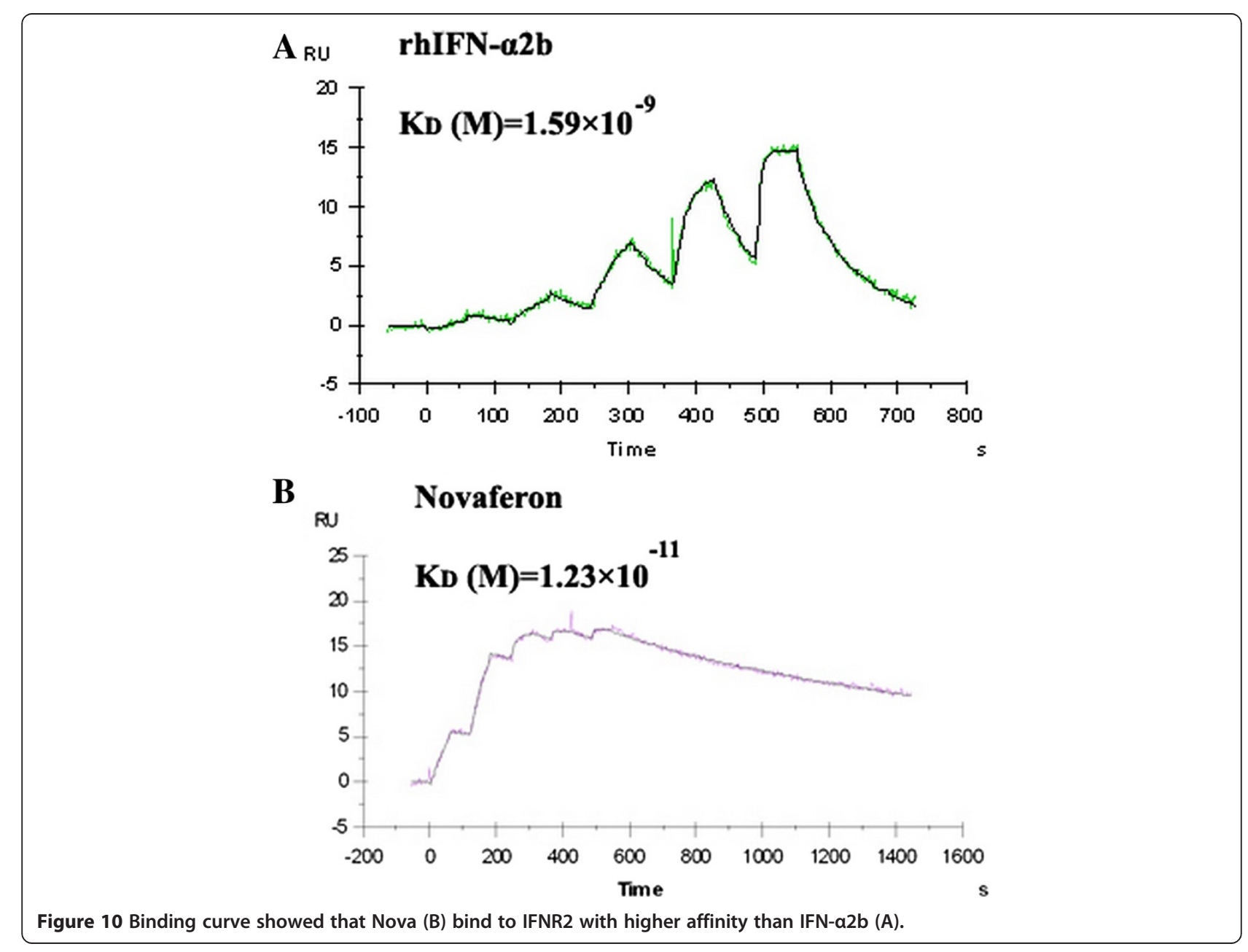


through S phase, and thus inhibited proliferation of the tumor.

Apoptosis, also known as programmed cell death, is a highly conserved eukaryotic cell suicide format [24]. Different from the anti-proliferate effect, apoptosis is removing aging cells through self-death or injury by the body and it is the genetic control of programmed cell death. Pro-apoptotic induction is one of the effective ways in anti-tumor therapy. Our study suggested that the ability of inducing apoptosis for Nova may be little stronger than rhIFN- $\alpha 2 b$, but this result need to be further confirmed.

Cysteine-requiring Aspartate Protease (Caspase) is a family of proteases, it plays important role in the process of apoptosis. Caspase-3, belong to the caspase family CED-3 subfamily [25], is a key enzyme regulating apoptotic process. In addition, caspase- 3 also plays a key role in chromatin condensation, DNA fragmentation during apoptosis. Caspase- 3 pro-enzyme stays in the cytoplasm of normal cells, at the early stages of apoptosis, it is activated and induces apoptosis eventually [26]. Up-regulated Caspase-3 expression demonstrates that nova exerts its' effect through inducing apoptosis in tumor cells [27].

Bax, also known as Bcl-2 associated protein $\mathrm{X}$, is another member of the Bcl-2 family [28]. It is a pro-apoptotic protein in the mitochondria-dependent apoptosis pathway. In healthy mammalian cells, Bax is inactive in the cytoplasm. Once triggered by signals, Bax is transferred to the mitochondrial outer membrane, and begin to induce mitochondrial release of apoptosis gene factor, triggering the apoptotic response [29]. Interferon could up regulate Bak and Bax in response to apoptosis [30], which is consistent with our data. Also, we observed the down-regulation of anti-apoptotic proteins $\mathrm{Bcl}-2$ in HepG2 tumor cells by Nova.

Ki-67, which is encoded by $M K I 67$, is a cell proliferationrelated nuclear protein used for diagnosing tumor cell proliferation [31]. Ki-67 expresses at the G1, S, G2 and mitosis phase, and is related with ribosomal RNA transcription [32]. Ki-67 staining is commonly used for diagnosis of malignant tumors. In our study; we observed that Ki67 in Nova treatment group is reduced than that in rhIFN- $\alpha 2 b$ group. The $\alpha$-SAM was found in tumor vascular smooth muscle cells, is a common cancer-associated fibroblasts which has tumor protective role, in consistent with Ki-67, our study demonstrate Nova could down regulate expression of $\alpha$-SAM and has better effect of antiangiogenesis in tumor blood vessels than rhIFN- $\alpha 2 b$.

Moreover, DNA contamination, endotoxin content, residual antibiotic activity and residual bacteria protein content of Nova is all below the limits of detection (data not shown). In a conclusion, Nova could be a potential powerful anti-tumor/virus drug; however, this also requires further clinical trials to verify.

\section{Competing interests}

The authors declare there is no conflict of interest.

\section{Authors' contributions}

JZW defined the research theme. ML and CMR designed methods and experiments, carried out the laboratory experiments, analyzed the data, interpreted the results and wrote the paper. DNP, LW and YHL co-worked on associated data collection and their interpretation. KG and MRW co-designed experiments, discussed analyses, interpretation, and presentation. All authors read and approved the final manuscript.

\section{Acknowledgements}

This work was financially supported by grants from the National Science and Technology Major Project (No. 2012ZX09304010). We thank the support given by our colleague and Genova Biotech.

\section{Author details}

${ }^{1}$ National Institutes for Food and Drug Control of China, No. 2 Tiantan Xili, Beijing 100050, China. 'Beijing Genova Biotech Company, Beijing 100050, China.

Received: 18 November 2013 Accepted: 20 January 2014

Published: 27 January 2014

\section{References}

1. Hanahan D, Weinberg RA: The hallmarks of cancer. Cell 2000, 100(1):57-70.

2. Bracarda S, Eggermont AMM, Samuelsson J: Redefining the role of interferon in the treatment of malignant diseases. Eur J Canc 2010, 46(2):284-297.

3. Roos G, Leanderson T, Lundgren E: Interferon-induced cell cycle changes in human hematopoietic cell lines and fresh leukemic cells. Canc Res 1984, 44(6):2358.

4. Sabel MS, Sondak VK: Pros and cons of adjuvant interferon in the treatment of melanoma. Oncol 2003, 8(5):451-458.

5. McLoughlin JM, Zager JS, Sondak VK, Berk LB: Treatment options for limited or symptomatic metastatic melanoma. Canc Contr: J Moffitt Canc Center 2008, 15(3):239-247.

6. Yoysungnoen $P$, Wirachwong $P$, Bhattarakosol $P$, Niimi $H$, Patumraj S: Effects of curcumin on tumor angiogenesis and biomarkers, COX-2 and VEGF, in hepatocellular carcinoma cell-implanted nude mice. Clin Hemorheol Microcirc 2006, 34(1-2):109-115.

7. Caraglia M, Dicitore A, Marra M, Castiglioni S, Persani L, Sperlongano P, Tagliaferri P, Abbruzzese A, Vitale G: Type I interferons: ancient peptides with still under-discovered anti-cancer properties. Protein Pept Lett 2013, 20(4):412-423

8. Adam L, Black PC, Kassouf W, Eve B, McConkey D, Munsell MF, Benedict WF, Dinney CPN: Adenoviral mediated interferon- $a 2 b$ gene therapy suppresses the pro-angiogenic effect of vascular endothelial growth factor in superficial bladder cancer. J Urol 2007, 177(5):1900-1906.

9. Wang H, Mao C, Li J, Xu J, Zhang R, Wang L, Du Y, Liu L: Recombinant human interferon-like proteins. In vol US 7,868,151 2011, B2:37.

10. Rath PC, Aggarwal BB: Antiproliferative effects of IFN-alpha correlate with the downregulation of nuclear factor-kappa B in human Burkitt lymphoma Daudi cells. J Interferon Cytokine Res: Offic J Int Soc Interferon Cytokine Res 2001, 21(7):523-528.

11. Hastie E, Grdzelishvili VZ: Vesicular stomatitis virus as a flexible platform for oncolytic virotherapy against cancer. J Gen Virol 2012, 93(Pt 12):2529-2545

12. Lan KH, Wang YW, Lee WP, Lan KL, Tseng SH, Hung LR, Yen SH, Lin HC, Lee SD: Multiple effects of Honokiol on the life cycle of hepatitis $C$ virus. Liver Int: Offic J Int Assoc Study Liver 2012, 32(6):989-997.

13. China TSBPSCotPsRo: Chinese Requirements for Biological Products (Version 2000). Beijing: China Food and Drug Administration; 2000:373.

14. Antonetti F, Finocchiaro $O$, Mascia M, Terlizzese MG, Jaber A: A comparison of the biologic activity of two recombinant IFN-beta preparations used in the treatment of relapsing-remitting multiple sclerosis. J Interferon Cytokine Res 2002, 22(12):1181-1184.

15. Huang SM, Harari PM: Modulation of radiation response after epidermal growth factor receptor blockade in squamous cell carcinomas: inhibition of damage repair, cell cycle kinetics, and tumor angiogenesis. Clin Cancer Res 2000, 6(6):2166-2174 
16. Zhu Q, Feng C, Liao W, Zhang Y, Tang S: Target delivery of MYCN siRNA by folate-nanoliposomes delivery system in a metastatic neuroblastoma model. Canc Cell Int 2013, 13(1):65.

17. Nagano H, Wada H, Kobayashi S, Marubashi S, Eguchi H, Tanemura M, Tomimaru Y, Osuga K, Umeshita K, Doki Y: Long-term outcome of combined interferon- $a$ and 5 -fluorouracil treatment for advanced hepatocellular carcinoma with major portal vein thrombosis. Oncology 2011, 80(1-2):63-69.

18. Ota H, Nagano H, Sakon M, Eguchi H, Kondo M, Yamamoto T, Nakamura M, Damdinsuren B, Wada H, Marubashi S: Treatment of hepatocellular carcinoma with major portal vein thrombosis by combined therapy with subcutaneous interferon- $a$ and intra-arterial 5 -fluorouracil; role of type 1 interferon receptor expression. Br J Cancer 2005, 93(5):557-564.

19. Bekisz J, Baron S, Balinsky C, Morrow A, Zoon KC: Antiproliferative properties of type I and type II interferon. Pharmaceuticals 2010, 3(4):994-1015

20. Sangfelt O, Erickson S, Castro J, Heiden T, Gustafsson A, Einhorn S, Grander D: Molecular mechanisms underlying interferon-alpha-induced G0/G1 arrest: CKI-mediated regulation of G1 Cdk-complexes and activation of pocket proteins. Oncogene 1999, 18(18):2798.

21. Sangfelt O, Erickson S, Grandér D: Mechanisms of interferon-induced cell cycle arrest. Front Biosci 2000, 5:D479-D487.

22. Sangfelt $\mathrm{O}$, Erickson $\mathrm{S}$, Grander D: Mechanisms of interferon-induced cell cycle arrest. Front Biosci: J Virt Libr 2000, 5:D479-D487.

23. Kalakonda S, Nallar SC, Gong P, Lindner DJ, Goldblum SE, Reddy SP, Kalvakolanu DV: Tumor suppressive protein gene associated with retinoid-interferon-induced mortality (GRIM)-19 inhibits src-induced oncogenic transformation at multiple levels. Am J Pathol 2007, 171(4):1352-1368.

24. Vermeulen K, Berneman ZN, Van Bockstaele DR: Cell cycle and apoptosis. Cell Prolif 2003, 36(3):165-175

25. Alnemri ES, Livingston DJ, Nicholson DW, Salvesen G, Thornberry NA, Wong WW, Yuan J: Human ICE/CED-3 protease nomenclature. Cell 1996, 87(2):171-172.

26. Lavrik IN, Golks A, Krammer PH: Caspases: pharmacological manipulation of cell death. J Clin Investig 2005, 115(10):2665.

27. Wang GH, Jiang FQ, Duan YH, Zeng ZP, Chen F, Dai Y, Chen JB, Liu JX, Liu J, Zhou $H$, et al: Targeting truncated retinoid $X$ receptor-alpha by CF31 induces TNF-alpha-dependent apoptosis. Canc Res 2013, 73(1):307-318

28. Murphy K, Ranganathan V, Farnsworth M, Kavallaris M, Lock R: Bcl-2 inhibits Bax translocation from cytosol to mitochondria during drug-induced apoptosis of human tumor cells. Cell Death Diff 2000, 7(1):102.

29. Renault TT, Manon S: Bax: Addressed to kill. Biochimie 2011, 93(9):1379-1391.

30. Panaretakis T, Hjortsberg L, Tamm KP, Bjorklund AC, Joseph B, Grander D: Interferon alpha induces nucleus-independent apoptosis by activating extracellular signal-regulated kinase $1 / 2$ and c-Jun NH2-terminal kinase downstream of phosphatidylinositol 3-kinase and mammalian target of rapamycin. Mol Biol Cell 2008, 19(1):41-50.

31. Scholzen T, Gerdes J: The Ki-67 protein: from the known and the unknown. J Cell Physiol 2000, 182(3):311-322.

32. Bullwinkel J, Baron-Lühr B, Lüdemann A, Wohlenberg C, Gerdes J, Scholzen T: Ki-67 protein is associated with ribosomal RNA transcription in quiescent and proliferating cells. J Cell Physiol 2006, 206(3):624-635.

\section{Submit your next manuscript to BioMed Central and take full advantage of:}

- Convenient online submission

- Thorough peer review

- No space constraints or color figure charges

- Immediate publication on acceptance

- Inclusion in PubMed, CAS, Scopus and Google Scholar

- Research which is freely available for redistribution

Submit your manuscript at www.biomedcentral.com/submit
C Biomed Central 